\title{
Fragen für Lehrer
}

\author{
Heiner Müller
}

In unseren Schulen lernen die Kinder

Den Fluß deklinieren und regulieren zugleich, In unsern Fabriken lernen sie Ökonomie, An Drehbank und Wandtafel das ABC Des Kommunismus und das Einmaleins Der Automaten. Die Worte haben Gewicht, Stoff, aus dem die Taten gemacht werden, Der Gedanke hat Folgen, das Ungefähre Ist das Gefährliche in den neuen Bereichen, Wo ein Kopf nicht ausreicht, zehn Köpfe nicht Ohne die Arbeit ihrer Erfindungen.

Die Kinder der Generation, die den Kapitalismus Ins Museum verwiesen hat, werden Maschinen baun, die ganze Fabriken herstellen. Der die neuen Maschinen beherrschen soll Muß genau wissen, was eine Maschine ist.

Viel wird verlangt von der Jugend, zu viel, Sagt der Lehrer, der zuwenig gelernt hat: (Tausend Jahre lang galt für ausgemacht, Vögel und Engel können fliegen, der Mensch Kann nicht fliegen, außer er ist ein Engel.

Wir sind keine Vögel, wir sind keine Engel, wir fliegen.)

Der gute Lehrer macht sich überflüssig.

Was er allein weiß, weiß er nicht.

Warum schläft ein Schüler auf der Schulbank?

Hat er keine Lust auf ein leichteres Leben

Durch Mathematik, wer verschweigt ihm,

Daß die Mathematik sein Leben erleichtert?
In unserem Land des täglichen Aufbaus

Wachsen die Kinder schnell: ihre Hände sind frei

Von den Fesseln, die wir getragen haben.

Ein >Ausbeuter`, wer ihnen die Arbeit abnimmt!

Ihre Gehirne sind leer von dem Ballast

Aus der Schule der Ausbeuter. Stopft sie nicht voll jetzt

Mit neuem Ballast: ein Kopf ist kein Aktenschrank,

Der Mensch ist kein Fragebogen, den man einfach ausfüllt.

Er ist die Frage, die sich selber beantworten muß.

Das Fahrrad muß nicht noch einmal erfunden werden,

An der Geschichte der Kriege lehrt, was

Den Krieg abschaffen hilft. Die Schule ist kein Museum,

Das Leben überholt die Lehrbücher;

Der Mensch ist kein Lexikon: er gebraucht es;

Er ist keine Maschine: sie arbeitet für ihn.

Der gute Lehrer sagt mehr, als der Schüler begreift,

Wissend: Das Leben, der größere Lehrer, wird

Seine Arbeit fortsetzen, wenn sie gut war.

Ein Motorrad fahren lernt man nicht auf dem Dreirad.

Einen Staat leiten lernt man nicht im Sprechchor.

Vergeßt nicht, wenn ihr die Staatsbürger von morgen erzieht, Was für ein Staat unser Staat ist: erzieht Staatsmänner.

(Gibt es Staatsfrauen? Haben die Frauen

in unserer Sprache kein Bürgerrecht? Arbeit für Dichter.)

Die Fragen die ihr das Leben stellt,

Stellt die Jugend dir, Lehrer, Betriebsleiter, Parteisekretär.

Dein Schweigen ist keine Antwort, deine Ausreden

Schaffen die Fragen nicht aus der Welt.

Allein gelassen mit ihren Fragen, ist sie allein

Mit den Lügen der Feinde an Radio und Bildschirm,

Und jede Minute ist da eine Minute zuviel. 